\title{
Health and social care workforce planning and development - an overview
}

Author 1: Keith Hurst, PhD, Independent Researcher and Analyst, Nottinghamshire, UK, keithhurst.research@yahoo.co.uk, 07711369594.

Author 2: Deirdre Kelley Patterson, PhD, Head of Centre for the Study of Policy and Practice in Health and Social Care, University of West London, London, UK, Deirdre.KelleyPatterson@uwl.ac.uk, 02082094133.

Corresponding author: Keith Hurst.

Corresponding Author's E-mail: keithhurst.research@yahoo.co.uk 


\section{Introduction, background and context}

Health and social care workforce planning and development (WP\&D) is an area that concerns all managers and practitioners because:

1. Their services employ, directly and indirectly, up to one in ten working people.

The English National Health Service's (NHS) pay bill, for example, accounts for $60 \%$ (£65.4bn) of healthcare expenditure; significantly more if undergraduate and postgraduate health and social care education and training costs are included.

2. Staffing can be historical and irrational; e.g., the United Kingdom (UK) general practitioner (GP) to patient ratios (in populations with similar demography and morbidity) range from 1:1224 to $1: 1958$ and hospital-based registered nurses range from $10 \%$ to $50 \%$.

3. Over- or under-staffed and imbalanced care teams have serious service-quality and cost implications, underlined in recent UK failing-service inquiry reports. The connection between staffing and service quality is irrefutable; i.e., staff to occupied bed ratios in toprated NHS hospitals is 1 to 6.9 compared to 1 to 7.3 in bottom-rated sites. Moreover, registered (e.g., qualified) practitioners in top-rated establishments equate to $46 \%$ vs. $42 \%$ in bottom-rated sites; i.e., there are more and proportionally more qualified staff in toprated service providers.

4. Job satisfaction and staff education/training, and ultimately staff retention, are jeopardised by poor WP\&D.

5. Health and social workforces are particularly sensitive to the oil-tanker syndrome; i.e., applying the brakes or pressing the accelerator when making staffing corrections can several years to have an effect.

(Kendall and Lissauer, 2003; Eames, 2013; Health and Social Care Information Centre, 2014; Hurst 2005)

In short, there's never been a more important time for arming planners with appropriate methods and data. Good quality health and social care services are underpinned by five cardinal principles, which are sensitive to WP\&D:

1. Free at the point of use throughout $24 \mathrm{hrs}$, with seamless pathways between acute and community service.

2. Safe, effective, efficient, devolved, open and accountable.

3. Designed to meet population needs, in which service users have choices.

4. Delivered by knowledgeable and skilled practitioners.

5. Epitomised by good employment practices; e.g., bullying isn't tolerated. (DH, 1993a; 1993b; DH, 2000; DH, 2001; DH, 2002a; Hodder, 1995; Hyde, 2001; and Richards et al., 2000).

Maintaining these five principles requires efficient and effective WP\&D; now a priority as service costs rise and poor quality issues raise alarms (Bosma and Higgins, 2002; DH, 2001; Tobin, 2002; Eames, 2013).

\section{Defining workforce planning and development}

The DH report (2002a, p.1.2) defined WP\&D as a dynamic process, where the right staff with the right skills are in the right place at the right time. Recently, a fifth right was added 'at the right price' owing to the financial constraints that service managers face. This means that the structures and processes used to determine present and future workforce size and mix need to be rigorous, using robust information supported by techniques that monitor service demands. 
The DH definition is premised on the notion that rigorously recruiting, educating, training and retaining an appropriate workforce is vital if the health and social care professionals are able to deliver better services without breaking the bank.

\section{The WP\&D framework}

There are several WP\&D models that help planners think about and act on intelligence.

\section{Weighing scales}

Workforce planning and development is sometimes represented as weighing scales (Figure 1); i.e., well-adjusted strategies achieve a balanced workforce. Efficient and effective WP\&D addresses the scale's demand and supply sides, underlined in DH (2001), which indicated a growing concern that manager, educator and researcher efforts to address demand and supply issues were falling down. Workforce planning and development, therefore, need to be embedded in a service's culture to solve staffing problems, meet healthcare demands and raise service standards - sometimes shown as a cyclical model (Figure 2).

\section{Figure 1 here}

\section{Improvement cycle}

The second model, therefore, represents WP\&D as an improvement cycle (DH 2000a), which, like the weighing scales, also addresses demand and supply. However, a spiral may be a better way to describe the loop, since there's an expectation that service standards are raised each time the circle is completed.

\section{Figure 2 here}

\section{Driving and restraining forces}

A third WP\&D model takes a broader and deeper view than Figure 1 and 2. Health and social care WP\&D force-field analyses took off after under-spending and understaffing meant that too few health and social care workers struggled to provide good care in challenging circumstances, which force field-diagrams clearly highlight. Increasing work pressures; e.g., growing and aging populations, diagnostic and treatment technologies, coupled with more informed and less deferential service users, and more rigorous inspection regimes, meant that practitioners face unrelenting challenges (Kendall and Lissauer, 2003), neatly summarised in Figure 3.

\section{Figure 3 here}

The Lattimer and Ashburner (1997) and DH (2002a) reports explain that good health and social care depends on staff overcoming these restraining forces, which requires:

1. Service providers to raise their game.

2. An acceptance that the biomedical model alone can't satisfy modern healthcare; i.e., health services should be based in the right care setting; e.g., preventing rather than curing may be more appropriate in primary care.

3. Increasing hospital throughput and transfer between health and social care requires hospital and community services to integrate.

4. Understanding and meeting the population's unmet needs. 
Workforce planner control these drivers and restrainers with variable success; e.g., only 9\% of staff in a one (now dated) survey felt that their W\&D efforts for meeting service demands were supported by their superiors and subordinates (Bosma and Higgins, 2002). One reason for their low confidence is that they had little choice when selecting methods for determining local workforce size and mix (Hurst, 2010). In contrast, after several good years when research and development (R\&D) and audits generated more WP\&D information and tools, planners are now overwhelmed by data and analytical methods; i.e., Health and Social Care Information Centre (2014) staff continually generate superb information, but around sixty individual datasets can be released each month, which can overpower even the best analysts. Consequently, managers and practitioners face a data rich but information poor situation and look to WP\&D staff for help.

Historically, there weren't enough WP\&D education and training programmes to help planners capitalise on these rich data (Richards et al., 2000; Tobin, 2002). Moreover, guidance and support may not address recent policy and practice developments, such as Healthcare Resource Groups and e-rostering, which help to shape the health and social care workforce (Appleby and Thomas, 2000; Audit Commission, 1992; Buchan and Edwards, 2000; DH, 2002a; DH, 2002b). Clearly, planners are addressing wide-ranging and changing health and social care policy and practice issues.

\section{Methodological issues}

Patients' needs differ; e.g., community population average ages vary by 20 years. Inconsistent service demands make it difficult for planners to approach WP\&D uniformly. Patients' care needs aren't always neatly divided into primary and secondary care, and staff shouldn't be categorised this way either. Unfortunately, fragmented and uni-professional WP\&D persist despite service integration; e.g., even today, WP\&D specific data tend to be organised along traditional workforce lines; e.g., medicine, nursing, therapists, scientists and social workers. Dissonance increases when workforce planners:

(i) Fail to build the rich data at their disposal into WP\&D.

(ii) Are faced with fitting square staffing models into round service holes.

(iii) Focus on staff mix inconsistently.

(iv) Weren't motivated to improve their strategies. (DH, 2000a; DH, 2002b)

However, evidence and guidance is improving; i.e., contemporary WP\&D literature reveals six broad staffing approaches, which coupled with appropriate data, can cross professional barriers (Hurst, 2010), thereby overcoming the silo problem.

\section{Professional judgement}

Also known as the Telford or manager-clinician consensus method, professional judgement is a long-standing, simple-to-use and an effective approach, which determines staffing levels with patient safety and service quality in mind (Telford 1979, Waite, 1986). In short, knowledgeable and experienced managers and practitioners decide their workforce size and mix using local variables and data. However, results are often labelled subjective and therefore mistrusted because professional judgement has no empirical foundation.

\section{Health-needs based WP\&D}


Sometimes called top-down or population-based, this method uses demographic and epidemiological data, collected systematically, to evaluate and adjust local staffing. Topdown datasets include:

(i) Population density and age.

(ii) Socio-economic; e.g., deprivation and housing.

(iii) Morbidity and mortality, such as lifestyle questionnaire scores

(iv) Full-time equivalent staff by grade.

(Durrand 1989; Piggott, 1988, Hurst 2005).

These variables and data provide a good base from which to determine workforce size and mix; i.e., older and very old people in the local population probably means that proportionally more old-age specialists will be employed. Obviously, to make this approach workable, staffing ratios, such as GP per capita need to be available. These staffing ratios are invaluable if local deprivation or geographic spread are major WP\&D variables. Classifying healthneeds based WP\&D variables and country-wide data can be challenging, so they can be grouped linearly as:

(i) Structure; e.g., staff to population ratios, which lead to

(ii) Process; e.g., contacts per practitioner, which lead to

(iii) Outputs and outcomes; e.g., immunisation rates.

The main drawback is that data stop at the organisation level; i.e., it may not be possible to 'drill down' because organisation-level data can't be aligned to localities, wards and departments, etc.

\section{Staff to case/patient ratios}

The third or caseload method, which includes data such as staff-patient contacts, is another important and useful WP\&D approach (Frame and O'Donnell, 1996; Luft, 1990; Waite, 1986). Buchan (2002) explains how stress-related job dissatisfaction is influenced by workload, which implies that getting caseloads right is imperative especially when staff and skills are short; i.e., caseload size should be governed by staff availability and their expertise rather than expecting the current team to satisfy and infinite demand. These data are useful for:

(i) Spotting services that have been cut owing to funding issues.

(ii) Improving recruitment and retention.

(iii) Adjusting practitioner workloads, so that they are equitable.

(iv) Determining how many staff and what mix is needed to meet current workloads.

This, like the top-down model, addresses both sides of the weighing scales. The information selected for caseload analysis is driven by the professional group under consideration (e.g., nurses differ from therapists). Specific data include:

(i) Service objectives;

(ii) Local population's age distribution and ethnic mix

(iii) New referral to repeat visits, admission and readmission rates

(iv) Staffing by grade. 
(v) Direct and indirect care time

(vi) Clerical and administrative work

(vii) Travelling time

(viii) Basic and post-basic education and other time-out issues.

(Audit Commission, 1999; Barrett and Hudson, 1997).

Caseload-based WP\&D tables are built from national data before local staffing is benchmarked; then it only remains to either modify workforce policies and procedures or adjust staffing to suit caseloads. However, merely attaching staff hours to patients and using the results to calculate total hours required aren't enough. Drennan (1990ab) explains how analysing dependency and workload data improves staffing estimations; i.e., merely assuming each contact requires the same staff time and effort is risky, which may under-or over-estimate true workload. Drennan (ibid) showed that similar-sized caseloads didn't always generate the same workload; i.e., caseload size didn't always equate to workload. Consequently, patient classification systems are needed.

\section{Dependency/acuity or workload methods}

There is overlap between method 3 (caseload analysis) and the fourth main staffing approach - the dependency-acuity method. The latter is more sensitive to patient-generated workloads than the former because it uses more than caseload size; this method addresses how sick or well patients are and, consequently, their reliance on staff. There are three related measures: (i) acuity indicates the patients' demand for technical care; (ii) dependency rates the patient's reliance on staff for fundamental care and (iii) staff hours per patient day that are required for each dependency/acuity category. Workload and the staff required, therefore, are governed by caseload size and patient diagnostic, treatment and care needs. Two datasets are collected and analysed concurrently:

(i) Each patient is assigned to a dependency/acuity group, ranging, typically, from category 1 (minimum) to category four (maximum assistance).

(ii) Dependency/acuity and corresponding care hours, collected systematically, using for example, non-participant observation or personal diaries, are entered into software, which generate the staffing numbers and mix required.

The staffing establishment needed, therefore, is the dependency/acuity indicator and a staffing multiplier. Unlike hospitals, the community is never full, which makes primary and community care workload measures especially important, so that workloads can be equilised. Consequently, dependency-acuity and staff hours have several valuable uses (Hurst, 2005 and 2010):

(i) Tracking and comparing acuity/dependency and workload over time and between areas.

(ii) Equalising, rationalising and prioritising work

(iii) Highlighting mismatches between actual staffing and workload-based estimations (now a formal requirement in the UK).

(iv) Indicating informal carers' contributions.

(v) Encouraging a common language between commissioners and providers.

(vi) Determining team size and mix.

(vii) Informing the process about how health and social services can work together.

The main downside is these complex methods demand more time and effort. 


\section{Timed-task methods}

Assigning patients to care pathways or compiling evidence-based care plans are common clinical practices. It's logical, therefore, to attach care hours to care plans. Total staff hours required to look after patients, therefore, means summing staff hours per patient day for all active care plans (Anderson, 1997). Method five is easily the most sensitive health and social care staffing method, but compiling the tasks and calculating the time required for each task is challenging, and tailoring each patient's care plan is time consuming, although electronic patient records can reduce construction and updating time.

\section{Regression analysis}

This method is unique because it's the only one among the six main health and social care WP\&D methods described here that can predict staffing requirements. In short, a service's main workload driver; e.g., hip-replacements, therapy sessions, along with related staffing data from best-practice sites, enter a linear regression analysis, which predicts staffing numbers and mix (Bagust et al., 1988). Workforce planners and their clinical colleagues usually have no difficulty selecting one driver to help them determine an appropriate workforce. Unlike other methods, on the other hand, there are few service-level data available for regression analysis, so planners may have to plan and implement detailed R\&D projects.

\section{Applying these methods}

The WP\&D armoury summarised above is sometimes criticised because:

1. Data are mostly retrospective (historical) and aggregated (collapsed/summarised) at the wrong service level.

2. Patient dependency/acuity ratings can be subjective and may be inflated by staff.

3. Invalid and unreliable scoring systems (that classify patients for example) are sometimes used.

4. Data processing errors aren't uncommon.

Also, despite their breadth, depth and power, no staffing method works in some settings. Multifaceted approaches (using at least two from the six), therefore, are often used in the same situation - a technique called triangulation. Health and social care services often raise unique issues; e.g., round-the-clock services mean that 5.2 full-time equivalent (FTE) staff are needed to provide one practitioner on every shift. Also, the two main workload variables: patient dependency/acuity and staff hours needed to look after the patients can be overwhelmed by, for example, travelling time between patients' homes and the likelihood that low-dependency patients may be out; i.e., a wasted journey. These problems don't happen with captive inpatients, so inpatient staffing formulas are more sensitive to direct (hands-on) patient care than associated work like travelling time (although, interestingly, travelling time is a staffing variable in single-room design wards), which make hospital staffing methods inappropriate for primary and community care. In short, several WP\&D issues and challenges emerge from the literature (Bosma and Higgins, 2002; DH, 1998; DH, 2001; DH, 2002b):

1. Planners need to create a modern workforce to meet local needs, develop services and improve efficiency and effectiveness.

2. Evaluating and investing in local workforces, reducing attrition and developing staff with the right skills, diversity and flexibility to meet changing service demands. 
3. Deliberately and substantially increasing practitioners in certain services owing to demographic and morbidity concerns raises funding, recruiting, education and training problems.

4. Workforce planners are required to exploit healthcare information and technology, so that services are more efficient and effective.

5. Service commissioners and providers should work with university staff to determine appropriate training numbers, recruit and educate them; an activity that should be prospective.

6. Developing planners' knowledge and skills to help them address gloomy but inescapable workforce predictions and to help them break-down professional barriers that restrict the way practitioners work.

7. Building and using robust WP\&D databases.

To meet these challenges, workforce planners are expected at least to:

1. Use health needs analysis to identify and fill workforce gaps.

2. Identify service demands; e.g., deprived and affluent areas will require different workforces.

3. Map and monitor the local workforce.

4. Plan and implement local workforce strategies.

(DH, 2001; DH, 2002a).

Given these issues, coupled with some pressing local staffing matters, such as service commissioner expectations, high-level WP\&D efforts should:

1. Collate and summarise national and local data to inform WP\&D.

2. Provide manual and computer-based programmes to help managers find short and longterm staffing solutions.

\section{Summary}

The right staffing number and mix who deliver good quality healthcare:

(i) Helps patients to live independently;

(ii) Raises their quality of life; and

(iii) Boosts people's economic contribution to the community.

Notwithstanding the increasing demand for services as population grows and ages, and as services move from hospital to community, flawed methods and disparate data are major barriers to effective WP\&D. If these barriers are overcome then sound WP\&D achieves good health and social care when appropriate care teams are in place. Issues in the literature that drive and restrain health and social care WP\&D are lucid and compelling, which leave planners in no doubt what is expected if they are to succeed and healthcare is to develop, and patients achieve the best outcomes. However, although WP\&D definitions and models in the literature are logical, clear and effective, they are imperfect. Workforce planning and development is about getting enough practitioners with the right skills to meet healthcare demands and to develop and implement new services, but planners don't always have the tools or data to help them determine the ideal workforce and there's a risk that WP\&D remains fragmented and uni-disciplinary when modern WP\&D should concentrate on integrated working. Recruitment and retention problems can easily stymie their best endeavours to get teams right, because the people that services need (i.e., staff with the right 
skills), even if they exist, aren't evenly distributed throughout the country. However, appropriately triangulated staffing methods can help planners equalise workloads among disparate groups and isolated practitioners - an important job satisfaction and staff retention issue, which is probably why Bolton et al., (1991) suggest that regular and systematic workforce reviews help planners justify their workforce. It seems vital, therefore, that planners have robust methods and supporting data at their fingertips.

\section{References}

Anderson, L. (1997), 'The role and resources required for the introduction of ward assistants using the GRASP systems workload method: a quantitative study', Journal of Nursing Management, Vol. 5, pp.11-17.

Appleby, J. and Thomas, A. (2000), 'Measuring performance in the NHS: what really matters', British Medical Journal, Vol.320 No. 7247, pp.1464-7

Audit Commission. (1992), Caring Systems, London, HMSO.

Audit Commission. (1999), First Assessment. A Review of District Nursing Services in England and Wales, London, HMSO.

Bagust, A. Prescott, J. and Smith, A. (1988), 'Numbering the nurses', Health Service Journal, Vol. 98 No. 5108, pp.765-766.

Barret, G. and Hudson, M. (1997), 'Changes in district nursing workload', Journal of Community Nursing, Vol. 17 Iss. 3, pp.4-8.

Bolton, J.P.G. Mant, J.W.F. Rees, S. and Costa, M. (1991), 'How many nurses?', Senior Nurse, Vol. 11 No. 5, pp.31-35.

Bosma, T. and Higgins, J. (2002), 'Primary Care Trusts: No can do', Health Service Journal, 112,5793 , pp.26-27.

Buchan, J. (2002), 'Human resources: Rallying the troops', Health Service Journal, Vol. 112 No.5807, pp.24-25.

Buchan, J. and Edwards, N. (2000), 'Nursing numbers in Britain: the argument for workforce planning', British Medical Journal, Vol. 320 No. 7241, pp.1067-1070

Department of Health. (1993a), Nursing in Primary Care. New World, New Opportunities, London, HMSO.

Department of Health. (1993b), The Named Nurse, Midwife and Health Visitor, London, HMSO

Department of Health. (1998), Working Together: Securing a Quality Workforce for the NHS, London, HMSO.

Department of Health. (2000), A Health Service of All the Talents, London, DH.

Department of Health. (2001), Investing and Reform for NHS Staff - Taking Forward the Plan, London, DH.

Department of Health. (2002a), Primary Care Workforce Planning Framework, London, DH.

Department of Health. (2002b), Liberating the Talents, London, DH.

Drennan, V. (1990a), 'Gathering information from the field', Nursing Times, Vol. 86 No. 39, pp.46-48.

Drennan, V. (1990b), 'Striving for fairer workloads', Nursing Times, Vol. 86 No. 40, pp.4849.

Durrand, I. (1989), 'Nurse/patient dependency in community nursing', Nursing Times, Occasional Paper, Vol. 85 No.5, pp.55-57.

Eames, S. (2013), 'Achieving a flexible workforce', Health Service Journal, Vol. 123 No. 6346, p.18. 
Frame, G. and O’Donnell, P. (1996), 'Community nursing: Weight lifters Health Service Journal', Vol. 106 No. 5224, pp.30-31

Health and Social Care Information Centre. (2014), http://www.hscic.gov.uk/pubs/ calendar, accessed May, 2014.

Hodder, P. (1995), 'Towards an integrated primary health care team', Value for Money Update', Vol.1, pp.6-7

Hurst, K. (2005), Primary care Workforce Planning and Development, Chichester, Wiley.

Hurst, K. (2010), 'Evaluating the strengths and weaknesses of NHS workforce planning methods', Nursing Times, Vol. 106 No. 40, pp.10-14.

Hyde, V (ed). (2001), Community Nursing and Health Care Innovations and Insights, London, Arnold.

Kendall, L. and Lissauer, R. (eds) (2003), The Future Health Worker, London, IPPR.

Latimer, J. and Ashburner, L. (1997), 'Primary care nursing. How can nurses influence its development?', NT Researcher, Vol.2 No. 4, pp.258-267.

Luft, S. (1990), 'Community: measuring patient dependency nursing', Nursing, Vol. 4 No. 9, pp.13-16.

Piggot, M. (1988), 'Making the numbers add up', Nursing Times, Vol. 84 No. 1, pp.36-37.

Richards, A. Carley, J. Jenkins-Clarke, S. and Richards, D.A. (2000), 'Skill mix between nurses and doctors working in primary care delegation or allocation: a review of the literature', International Journal of Nursing Studies, Vol.37 No. 3, pp.185-197.

Telford, W.A. (1979), 'A method of determining nursing establishments', Hospital Health Services Review, Vol. 5 Iss. 4. pp. 11-17.

Tobin, T. (2002), 'Primary Care Trusts: Called to account', Health Service Journal, Vol. 112 No. 5788 , pp.22-23.

Waite, R. (1986), 'Nursing by numbers', Nursing Times, Vol. 82 No 8, pp.40-42. 
Figure 1: WP\&D weighing scales

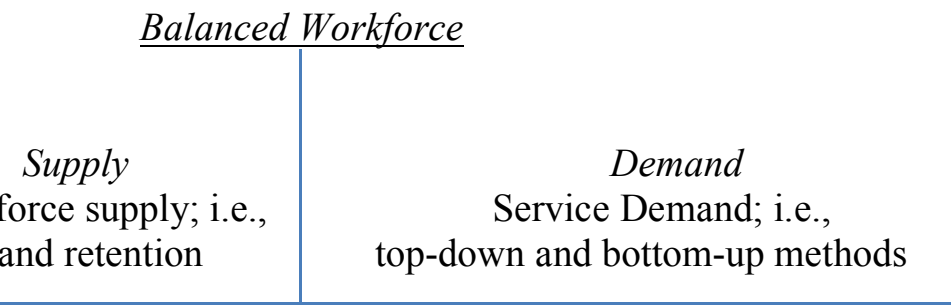

Figure 2: WP\&D cycle.

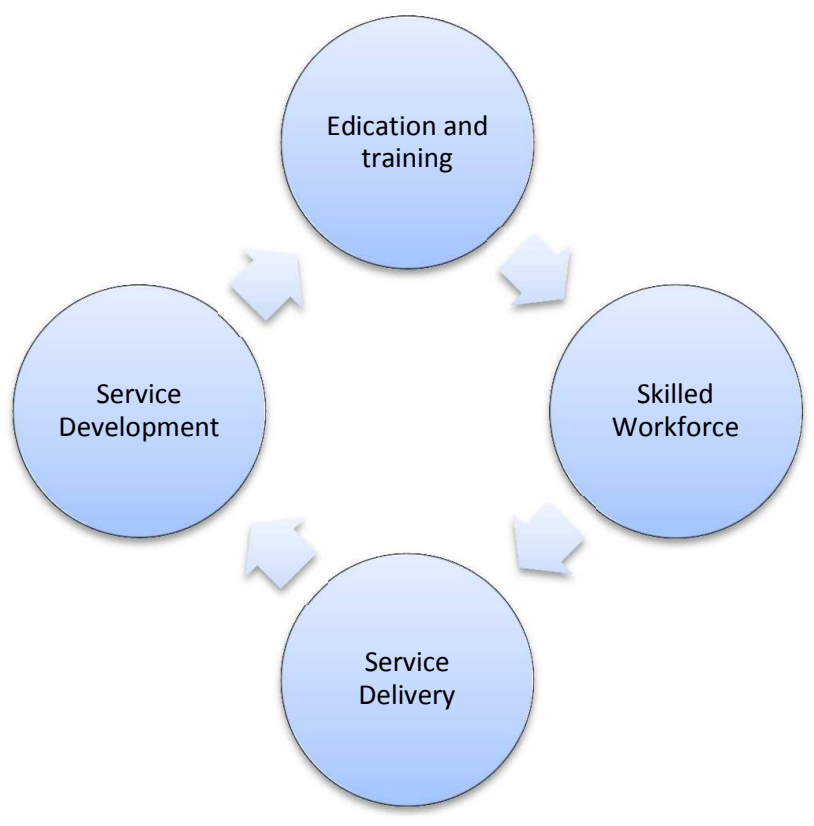

(c) Emerald Group Publishing Limited

This is a pre-print of a paper and is subject to change before publication. This pre-print is made available with the understanding that it will not be reproduced or stored in a retrieval system without the permission of Emerald Group Publishing Limited. 
Figure 3: WP\&D - a force-field analysis

\begin{tabular}{|l|l|l|}
\hline \multicolumn{1}{|c|}{ Driving } & \multicolumn{1}{|c|}{ Force } & \multicolumn{1}{c|}{ Restraining } \\
\hline $\begin{array}{l}\text { New policy; e.g., out-of-hours } \\
\text { services. }\end{array}$ & & Services failing to keep up \\
\hline $\begin{array}{l}\text { Secondary care in the } \\
\text { community and a move } \\
\text { towards a one-service approach } \\
\text { to health and social care. }\end{array}$ & $\begin{array}{l}\text { Weak primary, secondary and } \\
\text { social care interfaces }\end{array}$ \\
\hline $\begin{array}{l}\text { Continuous quality } \\
\text { improvement linked to WP\&D }\end{array}$ & & $\begin{array}{l}\text { Overwhelming WP\&D data sets } \\
\text { - it's hard for planners/analysts } \\
\text { to stay on top. }\end{array}$ \\
\hline $\begin{array}{l}\text { Extended practitioner roles. } \\
\text { Strengthened leadership at the } \\
\text { coalface. }\end{array}$ & $\begin{array}{l}\text { Professional silos (i.e., opaque } \\
\text { partitions between staff groups) }\end{array}$ \\
\hline $\begin{array}{l}\text { Prevention and caring now as } \\
\text { important as curing. }\end{array}$ & $\begin{array}{l}\text { Competing for limited resources; } \\
\text { can both be funded? }\end{array}$ \\
\hline $\begin{array}{l}\text { Local population's healthcare } \\
\text { needs and tackling inequalities. }\end{array}$ & $\begin{array}{l}\text { Inverse care law, ageing } \\
\text { population and increasing } \\
\text { chronic illness. }\end{array}$ \\
\hline $\begin{array}{l}\text { Patient choice is growing and } \\
\text { the consumer's voice is } \\
\text { strengthening. }\end{array}$ & $\begin{array}{l}\text { How to measure and report } \\
\text { consumer voices; e.g., the } \\
\text { Ultimate Question (family- } \\
\text { friendly) debate. }\end{array}$ \\
\hline $\begin{array}{l}\text { Recruiting staff } \\
\text { Retaining staff }\end{array}$ \\
\hline $\begin{array}{l}\text { The WP\&D methodological } \\
\text { armoury. }\end{array}$ & $\begin{array}{l}\text { One staffing method doesn't suit } \\
\text { every situation. }\end{array}$ \\
\hline $\begin{array}{l}\text { Technological developments } \\
\text { and service innovations. }\end{array}$ & \begin{tabular}{l} 
Unprepared staff; e.g., IT uptake. \\
\hline
\end{tabular} & \\
\hline
\end{tabular}

